\title{
Numerical modelling of the cyclic behavior of timber-framed structures
}

\author{
Relja Lukic $^{\mathrm{a}}$, Elisa Poletti ${ }^{\mathrm{b}, *}$, Hugo Rodrigues ${ }^{\mathrm{c}}$, Graça Vasconcelos ${ }^{\mathrm{b}}$

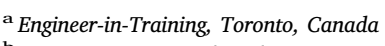 \\ b ISISE, Department of Civil Engineering, Campus de Azurém, University of Minho, Portugal \\ ${ }^{c}$ RISCO, School of Technology and Management, Instituto Politécnico de Leiria, Portugal
}

\section{A R T I C L E I N F O}

\section{Keywords:}

Timber construction

Earthquake engineering

Seismic design

Ductility

\begin{abstract}
A B S T R A C T
The present paper presents a study on the applicability of numerical models in predicting the global response of timber-framed shear walls during earthquake events. Based on previous in-plane cyclic testing of traditional timber frames with and without masonry infill, numerical models were developed to describe the cyclic response of traditional timber frame walls including flexural behavior, pinching and strength degradation. The numerical models were developed in the finite element software OpenSees with calibrated springs representing nailed connectors found in traditional half lap joints. Based on the calibrated models a study was conducted on the timber frame wall with brick infill model by varying wall configuration and analysing cumulative energy dissipation and the effect of slenderness and load capacity with increasing drift. A good correspondence was obtained with the experimental data and future work will include the application of the model to whole buildings.
\end{abstract}

\section{Introduction}

Ancient heritage is abundant with timber-framed structures that function as either shear walls within masonry buildings or as independent structural systems, resisting both lateral loads and gravity loads. In earthquake prone areas they have been used as seismic-resistant construction and their good behavior during seismic events has been documented and observed in several countries (e.g. Portugal, Italy, Greece, Turkey, Peru and Haiti) [1-4].

Timber shear wall systems are typically composed of internal braces forming an X-shape called the Cross of St. Andrew and are typically found in seismic countries such as in Italy and Portugal. Portuguese Pombalino buildings, introduced after the 1755 earthquake and subsequent tsunami and fire by the prime minister of the time, the Marquis of Pombal, consist of external load bearing masonry walls and internal timber-framed shear walls (Fig. 1a), called frontal walls [5]. Even though the city has not experienced significant seismic activity since 1755 (the return period is estimated to be 250 years), the seismic effectiveness of these buildings is unknown. However, it is expected that the seismic performance of Pombalino buildings is directly dependent on the timber frame walls and, thus, it is important to understand their mechanical behavior.

In Italy, the so called "casa baraccata", introduced after the 1783 earthquake by the Borbone house, has a timber frame also embedded in the exterior masonry walls [2]. Timber frame shear walls are encountered in several other countries, especially in the local vernacular architecture, and can be composed of various infill materials, ranging from brick and stone masonry to mud and cane. The timber is not only able to better resist horizontal loads, but it also provides a confining effect on the masonry structure improving its mechanical properties [6]. In Greece and Turkey a variety of timber-framed structures can be found $[1,7]$ and they have proved to resist well to seismic actions when appropriately maintained. The same can be said for other Balkan countries, e.g. Romania and Albania. Timber framed construction (quincha construction) in Peru also proved its efficiency during seismic events $[8,9]$. In this case, the walls are lighter and are infilled with interwoven bamboo canes. Quincha is used for upper floors, while the ground floor of traditional buildings is usually in adobe.

Timber frame construction systems are also present in typical vernacular architecture in non-seismic regions, such as Germany, France, the UK, and in general all northern European countries $[10,11]$. There is a great variability in terms of geometry, with bracing elements in the corners. Often, additional timber members are used as decorations, being also rounded (Fig. 1b).

The connections on timber frame construction are a key issue, as they control the in-plane behavior, particularly as regards the dissipative capacity of the timber walls. As there are very different types of connections, it is expected that different dissipative behavior is found, and this justifies the experimental research work that has been carried out in the last years on different timber frame systems [2,9,12-17]. Scarcer works are available from a numerical point of view. Kouris and Kappos [18] performed non-linear numerical analyses on traditional

\footnotetext{
* Corresponding author.

E-mail address: elisapoletti@gmail.com (E. Poletti).
} 


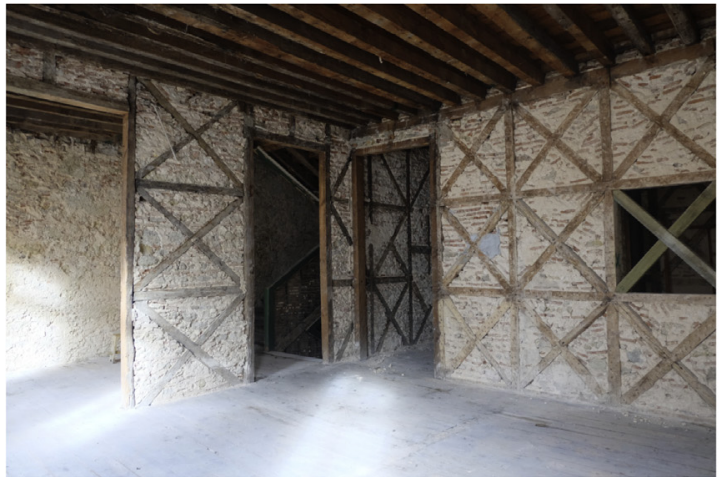

(a)

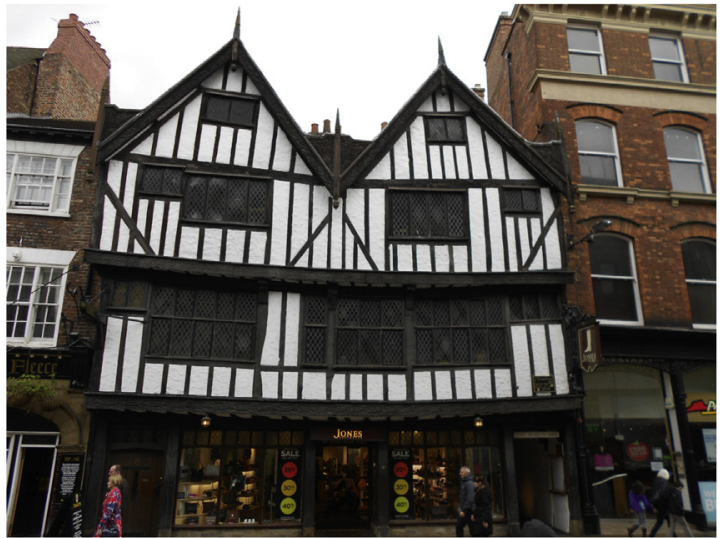

(b)

Fig. 1. (a) Frontal walls in (a) Pombalino building (c) Stellacci) and (b) timber-framed house in York, UK, XVI century (C) Poletti)

Portuguese half-timbered walls, first performing a detailed modelling of a wall, considering non-linear properties for the materials and modelling the contacts in timber elements and subsequently creating a simplified model using beam and link elements. Quinn et al. [9] modelled traditional Peruvian timber frame walls adopting semi-rigid spring elements to model the mortise and tenon connections of the wall. The springs were calibrated based on experimental results by using the components method, which is an analytical method that allows to calculate the joint stiffness assuming a semi-rigid model taking into account all the components of the loads (normal, shear and bending) [19]. Ceccotti and Sandhaas [20] used a hysteretic law to analyse the behavior of traditional timber frame walls. In the numerical model, the walls are represented by lumped masses and rotational springs and rigid elements represent the timber elements, being the global cyclic behavior of the wall given only by the behavior of the springs. For modelling a traditional Pombalino wall, Meireles et al. [16] introduced an analytical hysteretic law in a finite element software to describe the connections represented by means of spring elements. A macro-element was then developed to represent the frontal walls inside a masonry building. The hysteretic law was also implemented in an existing finite element model for other timber frame structures [21]. The use of hysteretic models can also be found for modern timber frames [22].

Due to the high computational cost of modelling a full-scale building using detailed nonlinear finite element analysis it is of paramount importance to have calibrated simplified nonlinear beam models to accurately represent structural elements. The advantage of such a model is that nonlinearity is confined to point hinges (lumped plasticity approach) that, once calibrated using plastic axial springs for a wall panel, can then be extrapolated for full-scale analysis of a real structure [18]. This type of model is capable of capturing the nonlinear response of the system, but the calibration of the connections is important to develop more realistic global behavior. A software that can incorporate various material models for the behavior of individual connections is necessary.

Following an experimental research carried out on the in-plane behavior of timber frame walls characteristic of Pombalino buildings [12], it was decided to define a numerical model on OpenSees platform [23] that describes appropriately the experimental results and that after this enables to evaluate the influence of some parameters in the inplane response of the traditional walls. Open System for Earthquake Engineering Simulation (OpenSees), developed by F. McKenna and G. L. Fenves with many other contributors at the NSF sponsored Pacific Earthquake Engineering (PEER) centre, is an object-oriented framework for simulating applications in earthquake engineering using finite element analysis [23]. It has the capability of performing many types of analysis including static push-over, static reversed-cyclic, dynamic time-series, and uniform or multi-supported excitations for inelastic time-history analysis for both structural and geotechnical systems. There exists a number of uniaxial-material, section and element models available as part of the OpenSees database. The database contains models for typical materials such as steel/reinforcing steel, concrete, elastic and elastic-plastic uni-axial materials, as well as other particular models including hysteretic models (Pinching4 model). It has great potential for timber modelling and various works can be found on such field. The OpenSees platform was recently used to analyse CLT wall panels under in-plane cyclic loading [24] and to model CLT mechanical connections under cyclic loading and compare the results with analytical models [25].

In the present work, different numerical approaches with different level of complexity were tested to describe the in-plane cyclic behavior of timber frame walls being their performance evaluated through the comparison with experimental results available. In addition, a study is provided assessing the influence of geometric parameters in the inplane behavior of timber frame walls.

\section{Brief summary of experimental results}

To study the seismic response of traditional Portuguese timber frame walls, under quasi-static in-plane cyclic tests were performed on real scale specimens [12]. Half lap joints were used for the connections between the elements of the main frame, while the diagonals were simply nailed to the frame (Fig. 2). The walls were tested under two levels of vertical pre-compression, being it applied on each post $(25 \mathrm{kN}$ or $50 \mathrm{kN}$ per each post), representing the condition encountered on site (Fig. 3). Additionally, different infill solutions were tested, namely brick masonry, lath and plaster and no infill. In general, the walls showed a good load capacity and deformation ability. Results greatly varied depending on the level of vertical pre-compression and on the presence of infill, which could alter the response of the wall from a shear to flexure (Fig. 5b).

Furthermore, in-plane cyclic tests and cyclic pull-out test were carried out on traditional joints with and without strengthening [26]. The selected joint was the one at the base of the wall, the half-lap teehalving joint, since post uplifting had such a great influence on the response of the wall. Diagonal elements were not considered (Fig. 4). For the in-plane cyclic tests, two vertical loads were adopted, as done for the wall tests (Fig. 4). From the results, it was apparent the main factors influencing the capacity of the joint were the presence of gaps and defects in the wood (knots and fissures), as they would constitute preferential paths for failure [12] as well as the type of strengthening and its ductility.

From the experimental campaign on timber frame walls (cyclic testing) [12] and traditional half lap connection (pull-out and cyclic testing) [26], the following observations could be deduced: 


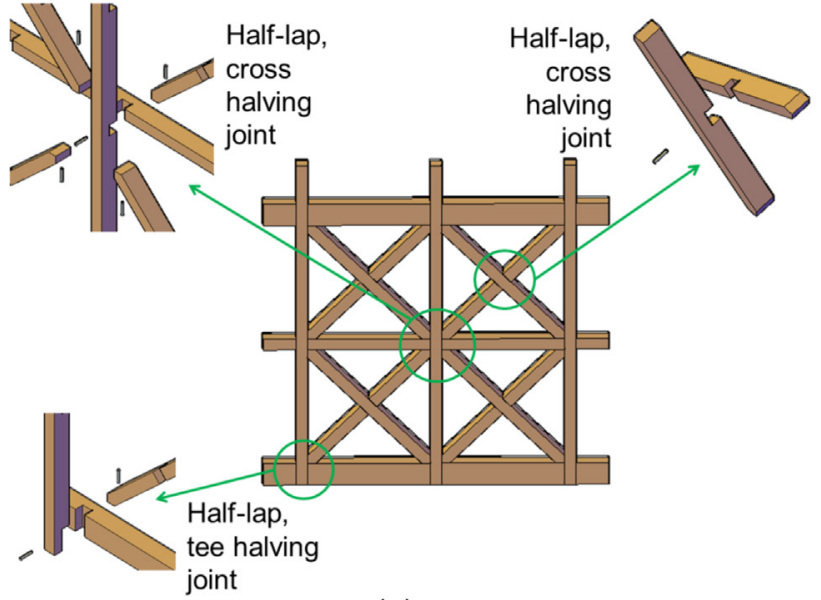

(a)

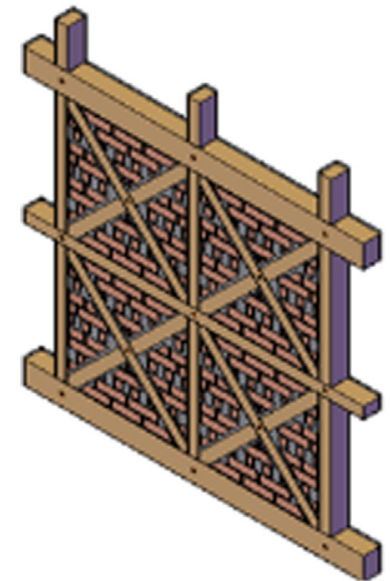

(b)

Fig. 2. Timber frame wall geometry; (a) without infill; (b) with brick infill.

1. Nonlinear behavior of the bottom connections influences the overall response of the walls leading to a predominant rocking (flexural) mechanism. This is translated into an uplift of the bottom joints, which was higher for lower vertical load levels. The observed strength degradation and pinching in the wall response (Fig. 5a) is related to the observed pinching behavior of the tested connections due to immediate loss of strength.

2. Infill walls tested at lower vertical load levels resulted in smaller opening of connections at the central and top beam because walls rotated as a whole, limiting local deformations in connections. For higher load levels the deformations were larger (Fig. 5a).

3. Timber frame walls experienced larger deformations and damages at the joints under both vertical load levels since absence of infill material created a prevalent shear resisting mechanism allowing for unrestricted deformations.

4. Deformation of the timber frame members was generally caused by uplifting of the posts from the bottom beam leading to elongations of the diagonals inducing high shear concentration within the central connection and resulting in failure. Movement of diagonals is larger in unfilled timber frame walls.

5. Unloading of the walls is influenced by the difficulty of the post to recover its original position due to the plastic deformation of the nail.

6. The quality of interlocking in the connections increases the loading capacity of the nail connector. Out-of-plane opening occurs due to asymmetry in thickness of half-lap connections (Fig. 5b).

For a full description of the experimental details and results, see [12] and [26].

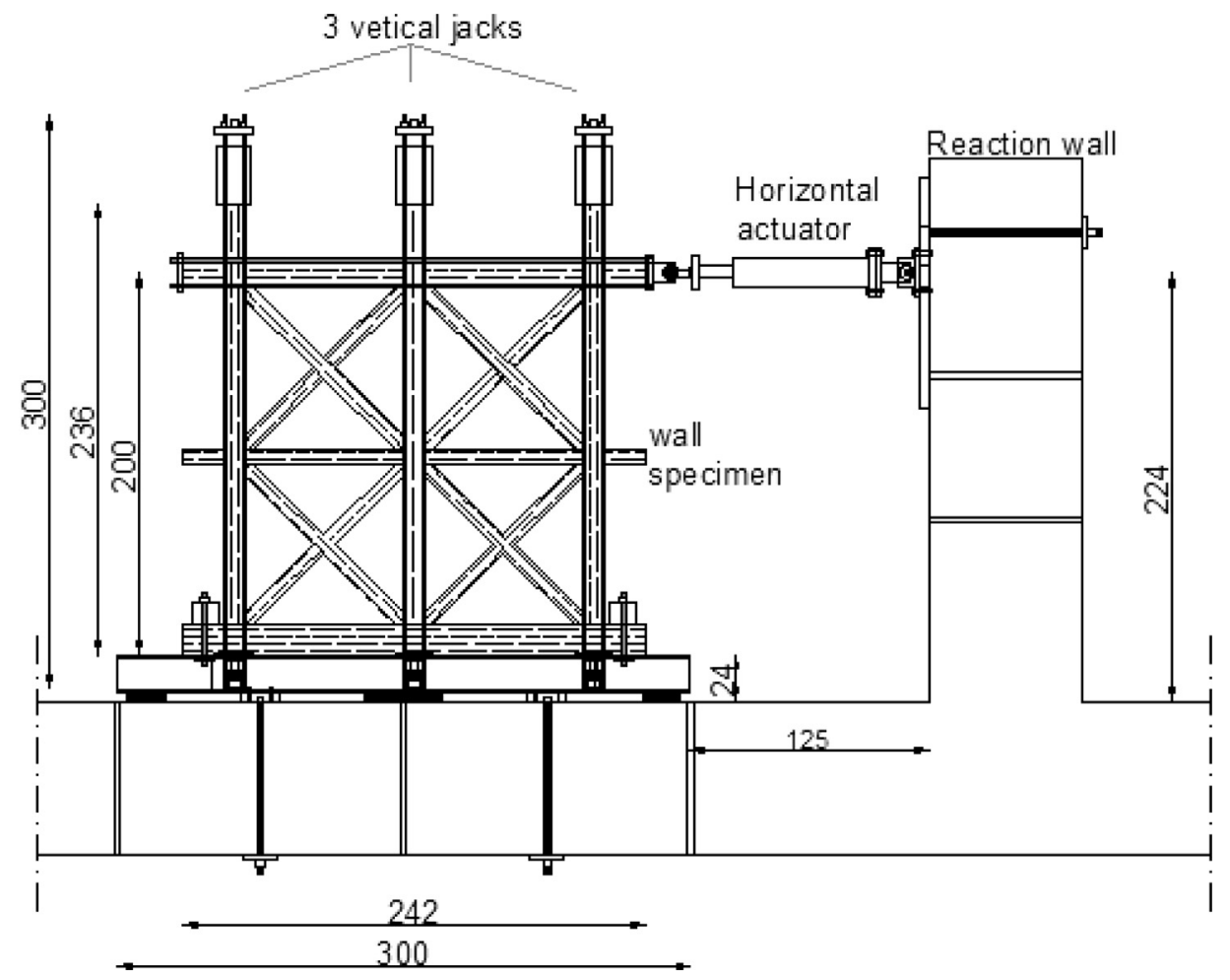

Fig. 3. In-plane test setup on timber frame walls (dimensions in $\mathrm{cm}$ ). 

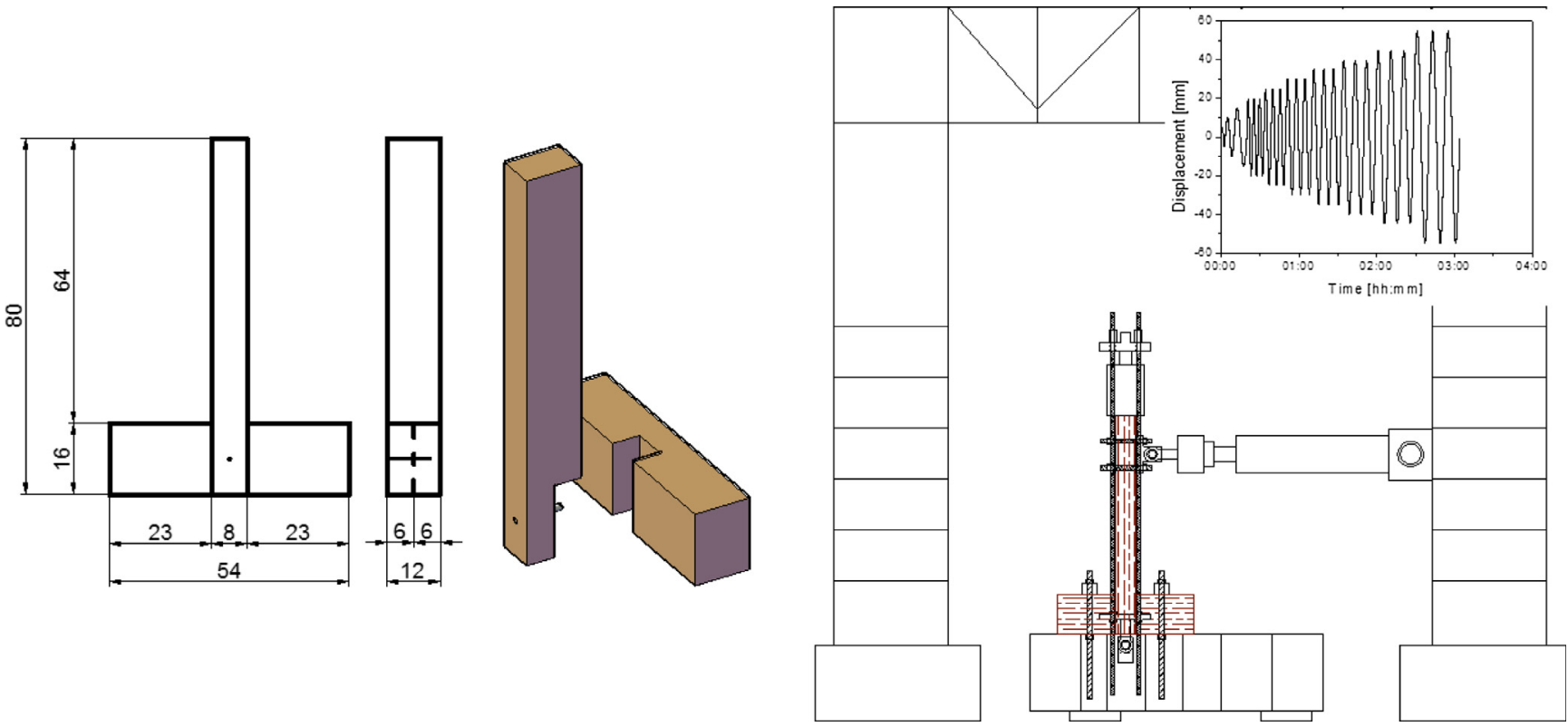

Fig. 4. Joint tested (dimensions in $\mathrm{cm}$ ) (left) and test setup (right) [24].

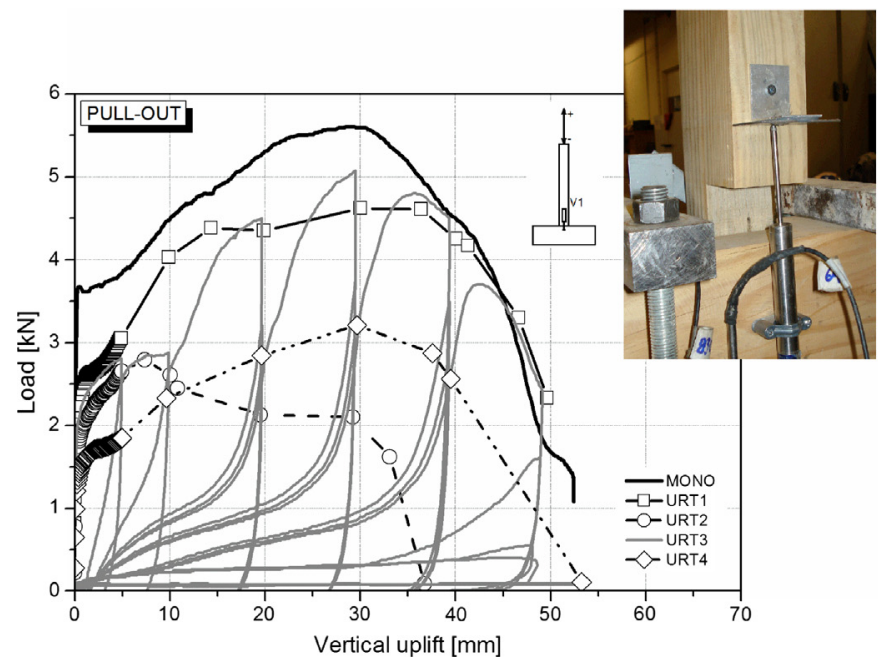

(a)

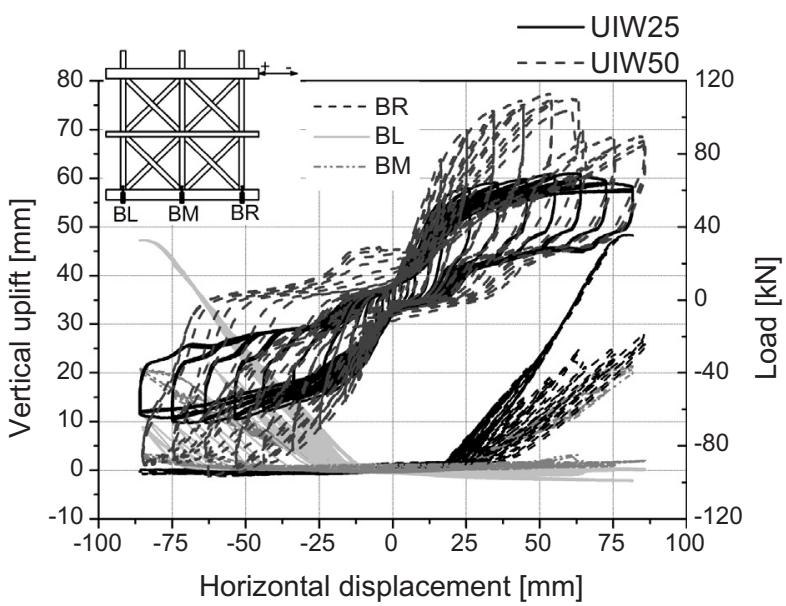

(b)

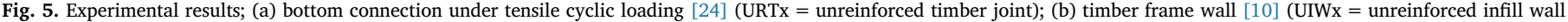
with a vertical pre-compression of $\mathrm{xkN} /$ post).

\section{Modelling traditional connections}

Given that it is intended to develop accurate numerical models that describe adequately the observed experimental behavior of the timber frame walls, it was decided to divide the work in two phases, namely: (1) modelling half-lap connections under different loading conditions aiming at deriving the material parameters controlling the mechanical behavior of the connection; (2) modelling the timber frame walls under in-plane cyclic loading. The main idea was to calibrate the nonlinear behavior of the bottom connections from the individual connection tests and then use the material model in the modelling of the timber frame walls.

The calibration of the tested half-lap connection was performed in OpenSees with a geometric model representative of the connection and considering similar loading and boundary conditions to the ones used in the experimental testing setup (see Fig. 6). The response of the tested half-lap connection was analyzed in order to calibrate two-node link elements acting as springs with the appropriate uniaxial material model

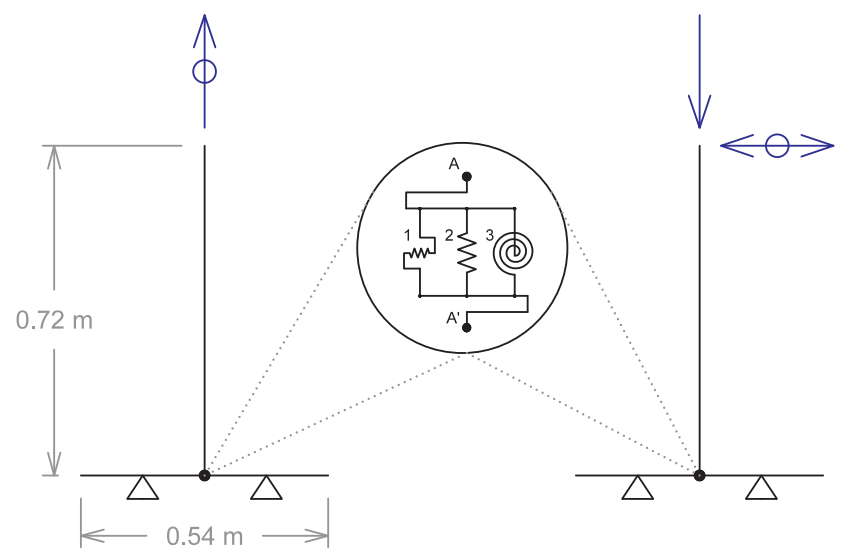

Fig. 6. Schematic of half-lap traditional connection: pull-out (left), in-plane cyclic (right) and the three behaviours calibrated $(1=$ shear, $2=$ axial, $3=$ rotational). 


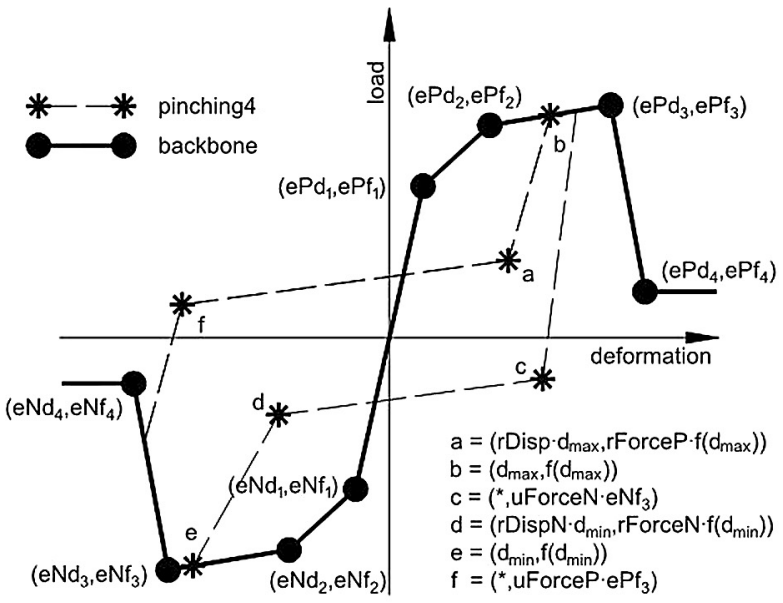

(a)

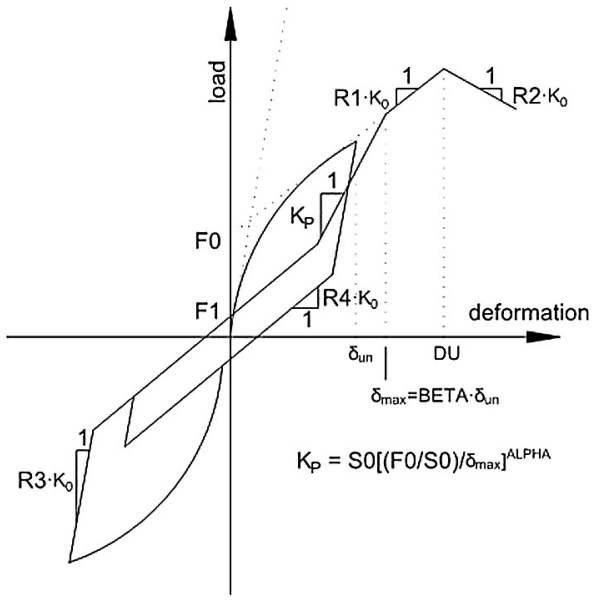

(b)

Fig. 7. Hysteretic models adopted: (a) Pinching4; (b) SAWS (adapted from [23]).

to represent the global hysteretic behavior according to three degrees of freedom, namely along axial and shear translations and rotation (Fig. 6).

Two hysteretic models were used for the calibration of the joints. Pinching4 [23] is a hysteretic model that represents a 'pinched' loaddeformation response and exhibits degradation under cyclic loading. Strength and stiffness degradation are taken into account considering unloading stiffness degradation, reloading stiffness degradation and strength degradation (Fig. 7a). Gamma parameters control the cyclic degradation of the model; ratios of force and displacement (rForce and rDisp) control unloading and reloading points.

The second hysteretic model adopted was SAWS, one-dimensional hysteretic model developed as part of the CUREe Caltech wood frame project [27]. This model also considers pinching and strength and stiffness degradation, relating all parameters to the initial stiffness $S_{0}$ (Fig. 7b)

The axial behavior was calibrated through the pull-out tests considering Pinching 4 hysteretic available in OpenSees, and the shear and rotational behavior was described based on the SAWS model from inplane quasi-static cyclic tests under levels of vertical pre-compression loading equal to $25 \mathrm{kN}$ and $50 \mathrm{kN}$.

The fitting between experimental results obtained in the pull-out tests and the numerical response of the connection modelled with $\mathrm{N}$ link elements having non-linear axial behavior (Pinching4 material model) is shown in Fig. 8a. The values obtained for the parameters describing the material model are presented in Table 1. It is observed that Pinching 4 model (Fig. 8a) was able to accurately predict the response obtained in the experimental tests, namely regarding the loading, unloading and re-loading branches (joint works only axially).

The shear and rotational behavior were calibrated based on the inplane cyclic tests, during which the joint is not subjected to axial forces, and assuming one behavior at a time (see Fig. 8b and c): (1) firstly, the non-linear behavior was considered to be governed by bending, for which the SAWS model was adopted for the rotational spring (3 in Fig. 6), assuming a linear elastic behavior in shear (1 in Fig. 6); (2) secondly, the spring was kept linear in bending ( 3 in Fig. 6) and the SAWS model was selected to govern the shear behavior of the spring (1 in Fig. 6).

By comparing the experimental and numerical force-displacement diagrams, it is observed that the SAWS model was able to accurately represent in both cases the envelope and stiffness degradation obtained in the experimental tests. Therefore, based on the results, Pinching 4 model was chosen for the definition of the axial spring and SAWS model was chosen to describe the behavior of rotational and shear springs.

\section{Detailed macro-model for timber frame walls without infill}

\subsection{Detailed macro-model adopted}

After calibrating the joints individually for each possible behavior, a 2-D numerical model was developed for timber frame walls in OpenSees, attributing the non-linearities to the joints themselves based on the calibrated links. The geometry of the model of the timber frame wall analyzed is representative of the specimen tested at the Laboratory of Structures at the University of Minho. Though the cells of the timberframed wall were not perfectly square $(84 \times 86 \mathrm{~cm})$ and given the different width of the elements $(16 \mathrm{~cm}$ bottom and top beam and $8 \mathrm{~cm}$ middle beam), a simplification to the member length was assumed to create a square frame consisting of four equal cells having the dimensions $0.95 \times 0.95 \mathrm{~m}^{2}$ for a total height and length of $1.90 \mathrm{~m}$. All members have the same cross-sectional areas $\left(0.8 \times 0.12 \mathrm{~m}^{2}\right)$ except the top and bottom beams $\left(0.16 \times 0.12 \mathrm{~m}^{2}\right)$. The modulus of elasticity for the timber elements is $11 \mathrm{GPa}$ according to experimental testing on the wood species Pinus pinaster [28].

Horizontal and vertical timber members of the timber frame wall were modelled in OpenSees with beam-column elements adopting a linear constitutive law in OpenSees. The diagonal bracing members are modelled as truss elements transferring only tensile and compressive forces. An elastic constitutive law was assumed for the material without shear deformations. Appropriate linear co-ordinate transformations were applied to transfer local coordinates of the members to global coordinates of the frame model, which is a mandatory step for OpenSees. The base nodes remained fixed, according to what was observed experimentally, while the global response was controlled by the calibrated springs.

The global response of the walls was controlled by the springs assigned to the joints. All end nodes of the members in the frame were duplicated at joints for the insertion of two-node link elements as springs in order to assign uniaxial material models applied in the corresponding direction of influence. The central connection was separated into 8 pairs of two-node links. For the 2-D model, three degrees-offreedom are considered for the links, namely vertical and horizontal displacements and in-plane rotations. The two-node elements have zero length and couples the rotations and the translations of connected nodes sharing the same global coordinates (Fig. 9 left).

Preliminary analysis showed that the parameters defining uniaxial 


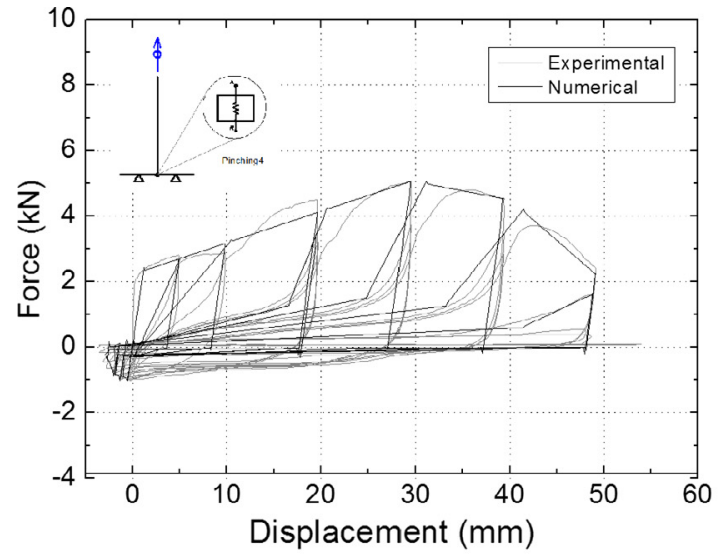

(a)

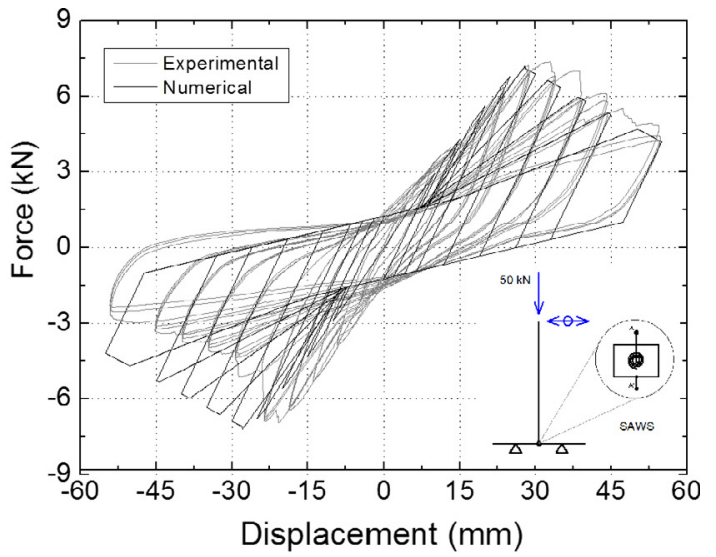

(b)

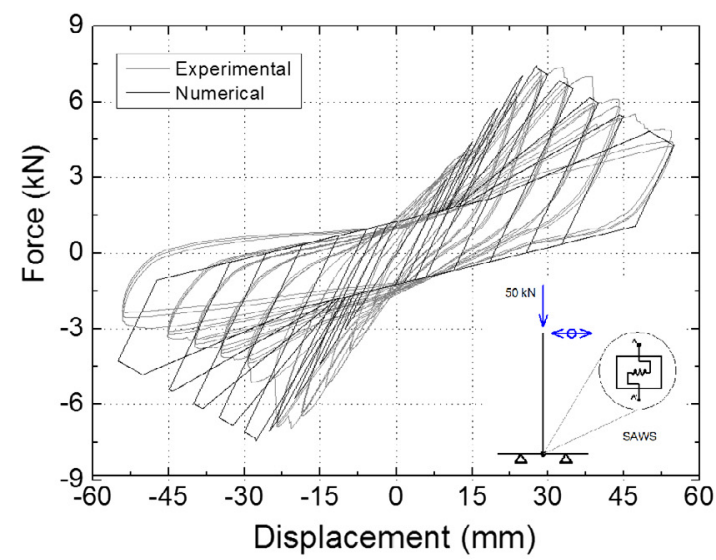

(c)

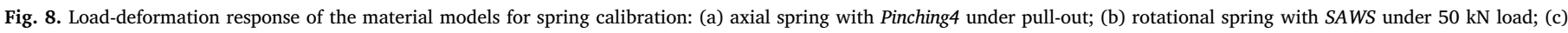
shear spring with SAWS under $50 \mathrm{kN}$ load.

material model for the spring obtained from the connection calibration had to be adjusted. High stress concentrations at the base and in the central connection led to problems of convergence resulting in the loss of nonlinear behavior. This issue was solved with additional uniaxial material models, namely elastic no-tension (ENT) and elastic-perfectly plastic gap (PP gap) material models used in parallel with the calibrated axial spring. ENT material model was used to have a connection with a high compressive stiffness (as the bottom half-lap joints had a very different stiffness in compression and in tension) while PP gap material model enables an initial gap in the connection before loading begins, simulating gaps present in the joints leading to an absence of immediate response (Fig. 10).

This means that in tension the elements experience only deformations similar to a cable with zero tensile resistance being stretched (Fig. 11, left) while in compression the elements behave like stiff rods with high compressive resistance (Fig. 11, right). The difference between ENT and PP gap material models is that the ENT material model does not account for a gap length where zero compressive resistance occurs.

Taking into account the response of the timber frame walls under inplane cyclic loading obtained in the experimental tests, it is considered that it should be controlled by the behavior of the bottom and central connections. The bottom connection controls mainly the flexural behavior of the wall, given that it is associated to the vertical uplift of the timber columns resulting from the detachment of the columns from the bottom beam. On the other hand, the stress concentration along the main diagonal for increasing lateral displacements leads to the shear cracking of the central connections.

Based on this, three different models were studied with different configurations of springs in an attempt to numerically describe the experimental results, mainly the nonlinear (hysteresis) loops in the global load-deformation curve and the displacement histories, namely at the base connections. In all the models, the nonlinearity is concentrated at the bottom and central connections (Fig. 12). In addition, different material models were assigned to the springs.

In all models, the diagonal members were assigned with Pinching4 material model in the axial direction combined with either ENT or PP gap elements in order to make sure they work only in compression and better represent the tolerance of the nail connector (these elements are not depicted in the schematics of Fig. 12 for simplicity). In order to replicate the shear damage observed in the central connection (central joint of the middle beam), the SAWS model was added in the axial direction within the definition of the horizontal beam two-node link for models 1 and 2, i.e. the central joint of the middle beam (Fig. 12).

In timber frame model 1 , the connections at the base were assigned with the material model Pinching4 in the axial direction. To improve convergence and to better represent the nail pull-out, an ENT material model with large stiffness in compression was used in parallel with Pinching4 material model at these joints (Fig. 12). This configuration was also used in the axial direction for all diagonal members. The SAWS material model was used in the rotational direction for the joints at the base while the shear response remained elastic to induce flexural (rocking) behavior.

The timber frame model 2 differs from the model 1 only at the bottom connections, where the ENT material model was replaced by a compression-only PP gap element with a high strength in compression, in parallel with Pinching 4 material model. A gap of $2 \mathrm{~mm}$ was defined as measured in the pull-out of the nail connectors. This element was used 
Table 1

Calibration of the material laws for springs.

\begin{tabular}{|c|c|c|c|c|c|}
\hline \multicolumn{6}{|c|}{ Pinching4 parameters for calibration of axial spring } \\
\hline Parameter & 1 & 2 & 3 & 4 & Limit \\
\hline pEnvelopeStress $\left(\mathrm{ePf}_{\mathrm{i}}\right)$ & 2.33 & 5.07 & 4.5 & 3.00 & - \\
\hline nEnvelopeStress $\left(\mathrm{eNf}_{\mathrm{i}}\right)$ & -1.00 & -0.90 & -0.84 & -0.16 & - \\
\hline pEnvelopeStrain $\left(\mathrm{ePd}_{\mathrm{i}}\right)$ & 0.0011 & 0.0295 & 0.0400 & 0.0500 & - \\
\hline nEnvelopeStrain $\left(\mathrm{eNd}_{\mathrm{i}}\right)$ & -0.0005 & -0.0010 & -0.0019 & -0.0030 & - \\
\hline gammaK & 0.00 & 0.00 & 0.00 & 0.00 & 0.00 \\
\hline gammaD & 1.00 & 1.00 & 1.50 & 2.00 & 0.50 \\
\hline gammaF & 0.00 & 0.00 & 0.00 & 0.00 & 0.00 \\
\hline gammaE & 10 & - & - & - & - \\
\hline rDisp pos./neg. & 0.8 & 0.8 & - & - & - \\
\hline rForce pos./neg. & 0.3 & 0.3 & - & - & - \\
\hline uForce pos./neg. & 0.01 & 0.01 & - & - & - \\
\hline \multicolumn{6}{|c|}{ SAWS parameters for calibration of rotational spring } \\
\hline \multicolumn{4}{|l|}{ Parar } & $25 \mathrm{kN}$ & $50 \mathrm{kN}$ \\
\hline \multicolumn{4}{|c|}{ Intercept strength of shear wall spring element, F0 } & 5.5 & 7 \\
\hline \multicolumn{4}{|c|}{ Intercept strength for spring element pinching branch, FI } & 0.65 & 1 \\
\hline \multicolumn{4}{|c|}{ Spring element displacement at ult. strength, DU } & 0.015 & 0.015 \\
\hline \multicolumn{4}{|c|}{ Initial stiffness of shear wall spring element, S0 } & 473 & 500 \\
\hline \multicolumn{4}{|c|}{ Stiffness ratio of the asymptotic line, $\mathrm{R} 1$} & 0.12 & 0.12 \\
\hline \multicolumn{4}{|c|}{ Stiffness ratio of the descending branch, R2 } & -0.065 & -0.09 \\
\hline \multicolumn{4}{|c|}{ Stiffness ratio of the unloading branch, R3 } & 2 & 6 \\
\hline \multicolumn{4}{|c|}{ Stiffness ratio of the pinching branch, R4 } & 0.055 & 0.055 \\
\hline \multicolumn{4}{|c|}{$\begin{array}{l}\text { Stiffness degradation parameter for the shear wall spring } \\
\text { element, alpha }\end{array}$} & 1.35 & 1.7 \\
\hline \multicolumn{4}{|c|}{$\begin{array}{l}\text { Stiffness degradation parameter for the spring element, beta } \\
\text { SAWS parameters for calibration of shear spring }\end{array}$} & 1.2 & 1.2 \\
\hline \multicolumn{4}{|c|}{ Parameter } & $25 \mathrm{kN}$ & $50 \mathrm{kN}$ \\
\hline \multicolumn{4}{|c|}{ Intercept strength of shear wall spring element, F0 } & 11 & 11 \\
\hline \multicolumn{4}{|c|}{ Intercept strength for spring element pinching branch, FI } & 0.65 & 1.4 \\
\hline \multicolumn{4}{|c|}{ Spring element displacement at ult. strength, DU } & 0.01 & 0.01 \\
\hline \multicolumn{4}{|c|}{ Initial stiffness of shear wall spring element, S0 } & 900 & 1000 \\
\hline \multicolumn{4}{|c|}{ Stiffness ratio of the asymptotic line, $\mathrm{R} 1$} & 0.1 & 0.12 \\
\hline \multicolumn{4}{|c|}{ Stiffness ratio of the descending branch, R2 } & -0.085 & -0.09 \\
\hline \multicolumn{4}{|c|}{ Stiffness ratio of the unloading branch, R3 } & 2 & 6 \\
\hline \multicolumn{4}{|c|}{ Stiffness ratio of the pinching branch, P4 } & 0.055 & 0.055 \\
\hline \multicolumn{4}{|c|}{$\begin{array}{l}\text { Stiffness degradation parameter for the shear wall spring } \\
\text { element, alpha }\end{array}$} & 1.9 & 1.9 \\
\hline \multicolumn{4}{|c|}{ Stiffness degradation parameter for the spring element, beta } & 1.2 & 1.2 \\
\hline
\end{tabular}

to induce the flexural rocking mechanism (one post uplifts while the opposite crushes).

The timber frame model 3 was defined with Pinching 4 material model in the axial direction and SAWS model in the rotational direction in the connections at the base. Nonlinearity in shear was added using the calibrated SAWS model from the individual connections with a larger intercept strength and initial stiffness of the spring. The Pinching4 model was also used in the axial direction of the diagonal bars joining at the central connection. In this case, it was decided not to use gap elements in parallel with Pinching4 model in the base connections.
Instead, a larger compression backbone was defined to avoid crushing of the bottom beam.

The non-linear cyclic analysis was conducted by applying displacement increments of $0.1 \mathrm{~mm}$ with the following displacement cyclepeaks: $15 \mathrm{~mm}, 30 \mathrm{~mm}, 40 \mathrm{~mm}, 50 \mathrm{~mm}, 60 \mathrm{~mm}$, and $70 \mathrm{~mm}$. The cyclic analysis was performed only up to $70 \mathrm{~mm}$, even if the experimental tests went up to $90 \mathrm{~mm}$ with a softening behavior. This difference is associated to the early failure of the timber frame wall without infill and subjected to a vertical pre-compression load of $50 \mathrm{kN} /$ post (UTW50) at $70.85 \mathrm{~mm} \mathrm{[12]}$. In the present model it was not possible to capture the failure of the joint. Lateral deformations were measured at top and mid height of the frame and in addition, the uplift of the bottom left and right columns from the bottom beams was also recorded. The top lateral displacements was used to derive the force-displacement hysteresis diagrams.

\subsection{Analysis and discussion of the results}

The force-displacement diagrams obtained in the numerical modelling using the different timber frame models are presented in Fig. 13. In addition, the comparison between experimental and numerical vertical displacements (uplift) of the lateral columns as the result of the detachment from the bottom beams is also provided. The analysis of the results enables to observe that models 2 and 3 are able to reproduce reasonably well the initial stiffness and maximum lateral strength (monotonic envelop). Lower performance is attributed to model 1 in achieving this goal, showing a lower stiffness than the ones obtained in the experimental tests. Increasing the tension backbone of Pinching4 model at the base connections does not result in the increase of the initial stiffness and overall capacity, but instead results in higher uplift. The lateral strength obtained in the numerical simulation of the timber frame model 1 is also lower than the one recorded in the experimental tests. Another difficulty of model 1 is attributed to the low representativeness of the unloading branch. Nevertheless, numerical model 1 is able to reproduce damage (shearing) of the middle beam at the central connection and sliding of diagonal members as it is shown in the deformed shape of Fig. 14a, which is in accordance with damages achieved in the experimental testing.

The load-deformation response at the top of the frame is also not very well captured both in model 1 and model 2 , given that they are not able to represent the energy dissipation at the central connection.

The numerical model results in terms of force-displacement diagrams and experimental uplifts are only comparable in the range where experimental data is able to be represented by the model due to the local collapse of the central beam, which is identified by the sudden drop in the lateral load capacity in the experimental force-displacement diagrams. Model 2 over-estimates the experimental uplift by 3.4 times at $59 \mathrm{~mm}$, whereas model 3 underestimates the uplift by approximately $30 \%$ at $12 \mathrm{~mm}$ compared to the experimental uplift (Fig. 13b,c).

The deformed shape of model 2 (see Fig. 14b) presents vertical

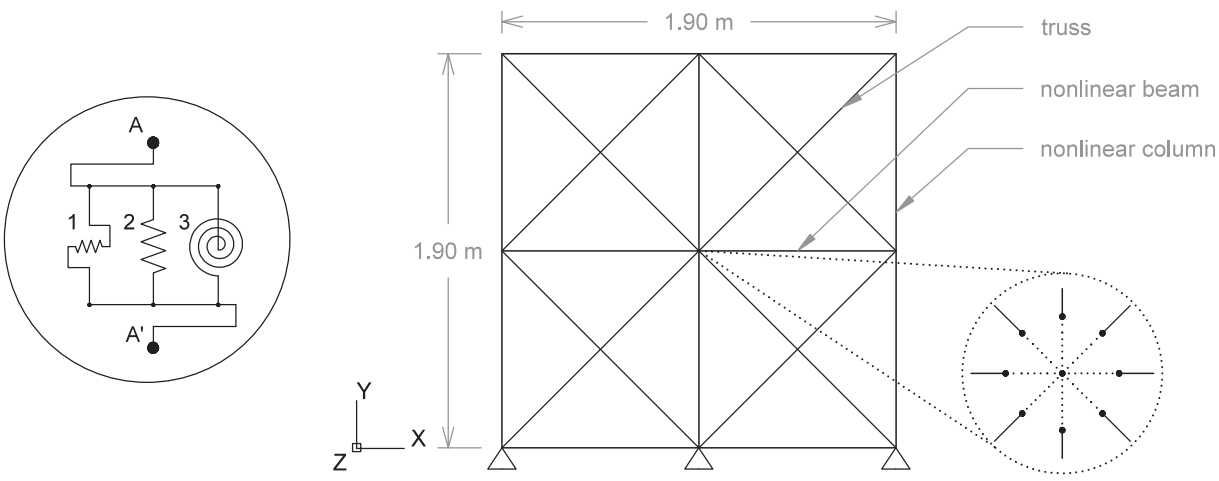

Fig. 9. Schematic of the numerical model: two-node link element (left) and frame geometry (centre). 


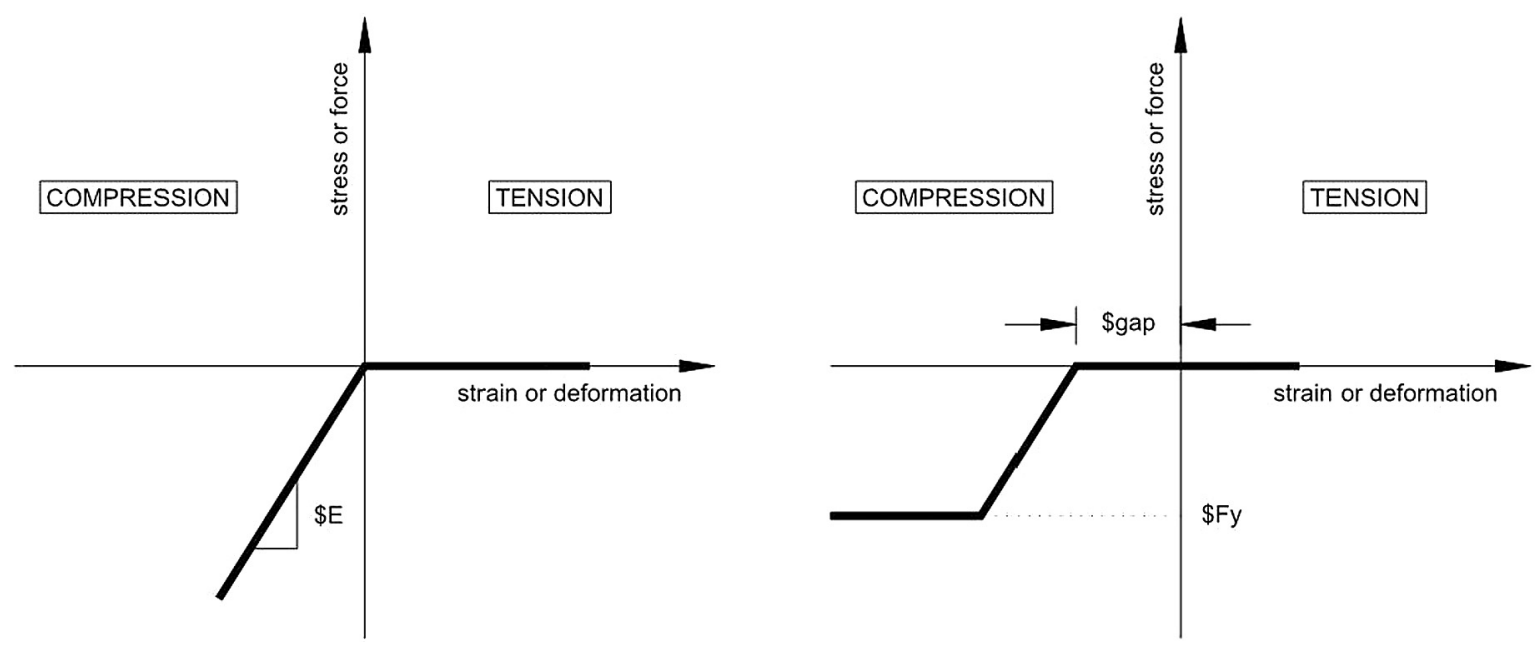

Fig. 10. Elastic no-tension (left) and elastic-perfectly plastic gap (right) elements [23].
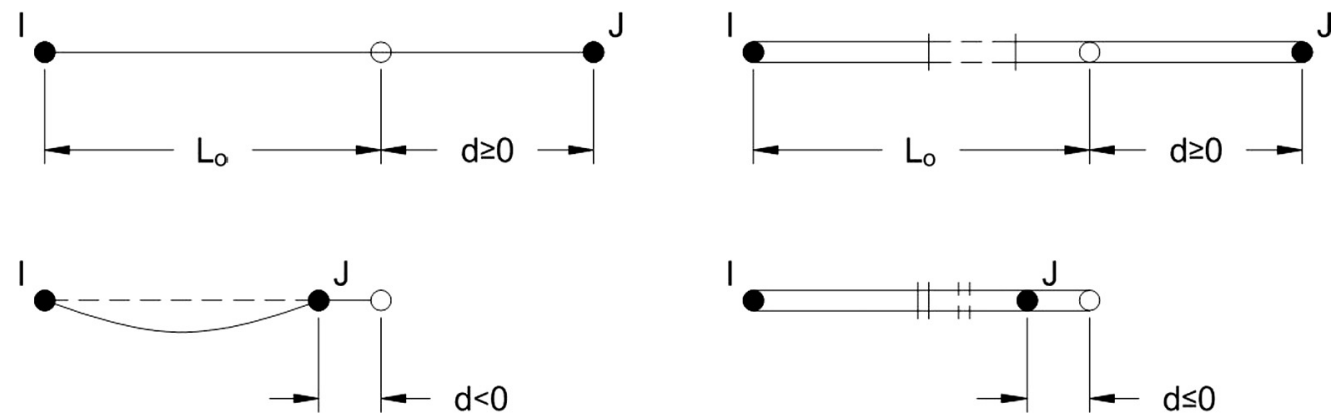

Fig. 11. Physical meaning of ENT and PP gap material models: Tension-Only (left), Compression-Only (right).

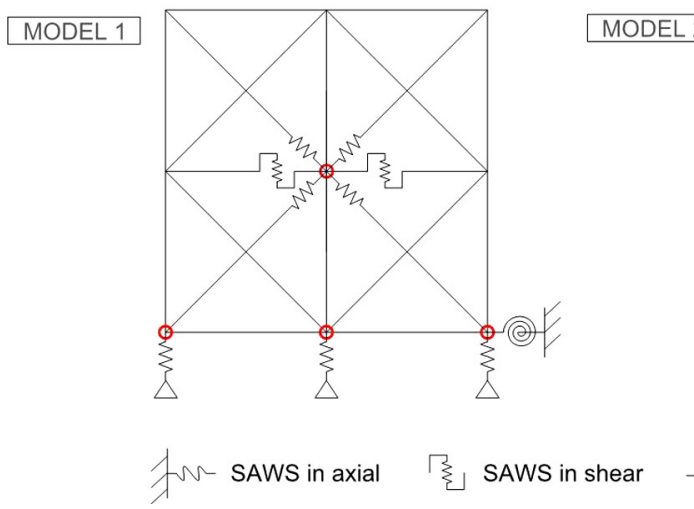

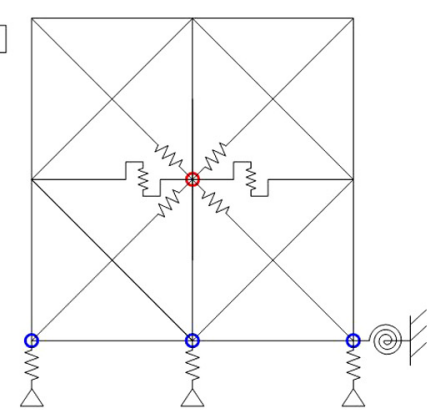

SAWS in rotation

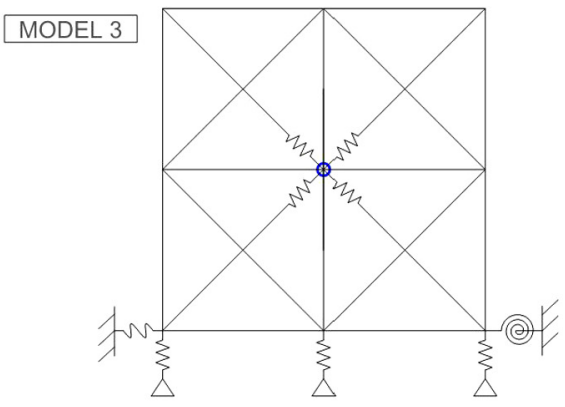

○ Elastic No-Tension O Elastic PPGap

Fig. 12. Studied models for timber frame wall with varying locations of nonlinearity.

uplift of the vertical columns from the bottom beam and no sliding of the diagonal. In addition, some noticeable damage in the central connection can be observed through local displacements.

Timber frame model 3 does not replicate neither the sliding of the diagonals nor damage in the central connection. The resisting mechanism is developed mainly by shear at the base as shown by the global lateral movement of the frame (Fig. 14c) but this is considered to be incompatible with the deformed shape found in the experimental tests, as no sliding at the base was recorded (see Fig. 14d).

The comparison between experimental and numerical results was complemented with the comparison between numerical and experimental cumulative energy dissipation, see Fig. 15. The cumulative energy dissipation was calculated from the numerical force-displacement diagrams through the area of each hysteretic cycle at the maximum displacement in the positive direction, i.e. when the wall was being pushed (positive displacements in the graph). Notice that some asymmetry on the experimental response was observed due to features of the test setup during the cyclic loading, which justifies the possibility of considering only the positive part of the diagrams without losing accuracy.

Among the numerical models, it is seen that timber frame model 1 presented slightly higher energy dissipation when compared with timber frame models 2 and 3. However, all models presented lower energy dissipation than the experimental test. These results indicated that the numerical models present some weakness in describing the dissipative behavior of the timber frame walls, which is mainly associated to the deficiencies in describing the stiffness of the unloading branch with the selected material models for the springs. The main reason is related to the hysteresis loops of model 1, which are smaller when compared to the others in the unloading branch, the reloading 


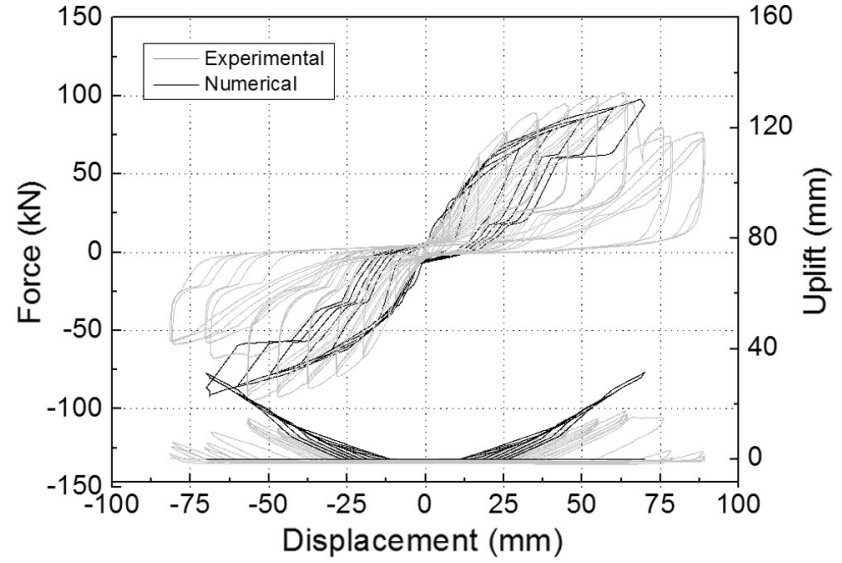

(a)

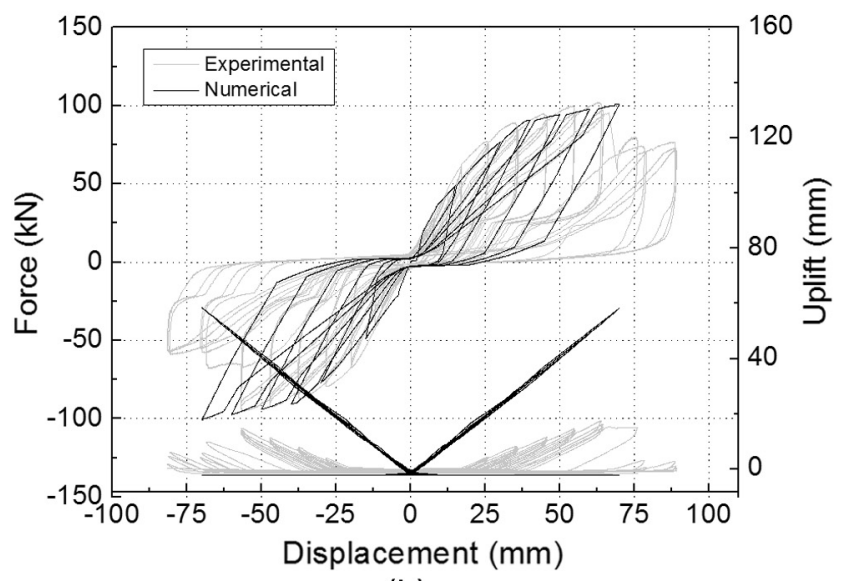

(b)

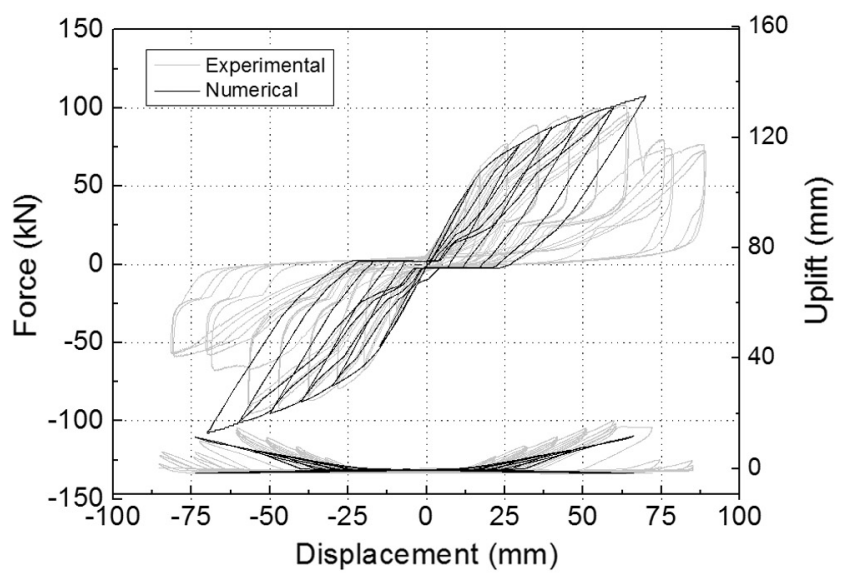

(c)

Fig. 13. Comparison between experimental results and model output: (a) timber frame model 1; (b) timber frame model 2; (c) timber frame model 3.

branch is higher, presenting almost no stiffness and strength dissipation, thus leading to a higher energy dissipation.

Comparing the performance among the three models it is considered that even if some differences were found, timber frame model 2 performs better in the fitting of the experimental global response. The concentration of the nonlinearities at the base and in the central connection proved to be reasonably accurate. The adoption of elastic $P P$ gap elements for the bottom connections in conjuntion with Pinching4 material models appeared to induce the nonlinear (hysteresis) response while the SAWS model controlled the rocking behavior. On the other hand, the adoption of the Pinching4 material model in conjuntion with elastic no-tension law for the diagonals results in the diagonals acting in compression only. Remarkable damage of the central connection and sliding of the diagonals is not seen in terms of local displacements, possibly due to the gap material at the base that restricts movement of the diagonals and prevents shearing of the middle beam.

\subsection{Simplified calibration of the timber frame with brick infill}

Aiming at simulating timber frame walls with brick masonry infills, also tested experimentally, it was decided to update the timber frame model 2 to include the confining and stiffening effect of masonry infill in a simplified way, by cancelling nonlinearities in the central connection and only controlling global response by means of nonlinear connections at the base. From different of experimental results on frontal walls $[12,16,17]$ it was observed that infill was behaving as a block, with minor cracking in both bricks and mortar joints. In mixed structures, masonry provides a stiffening effect of the enclosure structure, impacting the deformation capacity of the joints. This means that a stiffening of the joints can, in a simplified way, simulate masonry infill. In case of timber frame with brick infill, it was observed that inplane cyclic response was mostly governed by flexural behavior much associated to uplift of the columns resulting from their detachment of the bottom beam and further rocking of the wall.

Stiffness of the diagonal members and of the connections was also increased to $16.5 \mathrm{GPa}$. The backbone of the tension side of Pinching4 material model was also updated to better capture the total load capacity and initial stiffness. The SAWS model used to capture the rotational behavior at the base connections was adjusted to include the large intercept strength of the spring for the pinching branch.

By comparing the experimental and numerical force-displacement diagrams shown in Fig. 16, it is seen that the model is comparable to the results of timber frame wall with brick infill tested with a vertical precompression load of $50 \mathrm{kN}$ in each post (UIW50) up to the first failure of the specimen occurring at $70 \mathrm{~mm}$ horizontal displacement. After this point, the response of the wall is mostly controlled by the failed joint, which cannot be acquired by the numerical model. Large asymmetry exists in the experimental results, which the model is not able to replicate. The model overestimates the uplift by approximately 2.6 times at $66 \mathrm{~mm}$ compared to the experimental of $25 \mathrm{~mm}$ (Fig. 16). This difference may be due to the concentration of the non-linearities at the base of the wall (therefore the damages). In this condition, the wall presents a rigid deformation by rotation of the wall around the bottom corners and the joints of the central beam can be considered mostly rigid. This deformation pattern is possible due to the detachment of the posts from the bottom beam. The uplift is greater than the one obtained in timber frame wall without infill, as expected, given the higher predominance of flexural/rocking behavior. Therefore, the model appears to be able to replicate the predominant rocking mechanism, as is typical of half-timbered walls with brick masonry infill. No crushing of the middle post at the central connection is noticeable compared to the experimental damage.

\subsection{Analysis of the influence of the aspect ratio of the timber frame walls}

A complementary study was conducted after the calibration of the numerical model on the timber frame with brick infill considering different geometric configurations. Squat and more slender walls were considered, taking into account the different possibilities that can be found for these walls, see Fig. 17.

The influence of the height to length ratio on the lateral response of the wall is analyzed based on the initial stiffness and lateral load capacity. Additionally, the monotonic lateral load-lateral drift diagrams and cumulative energy dissipation obtained for the different walls geometry configurations are also presented and analyzed. The geometric configurations are analyzed and compared by imposing a maximum lateral drift of $10 \%$, while the experimental model reached a 


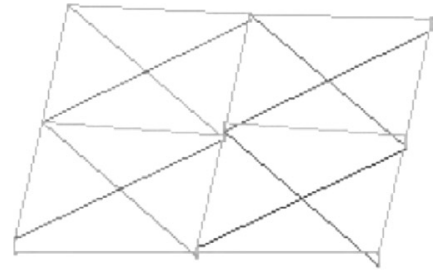

(a)

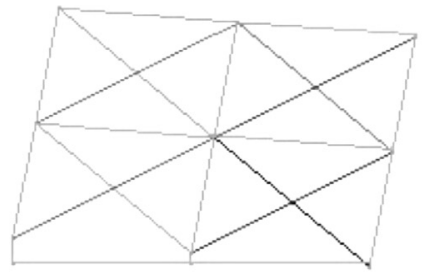

(b)

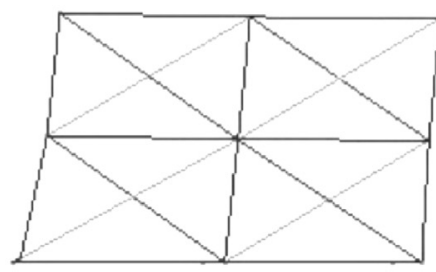

(c)

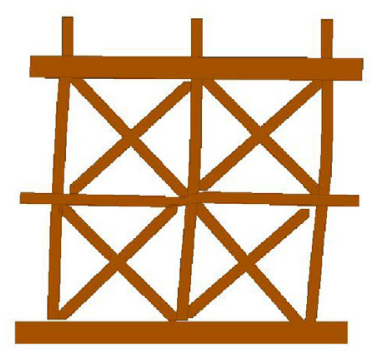

(d)

Fig. 14. Deformed shape of numerical models: (a) timber frame model 1; (b) timber frame model 2; (c) timber frame model 3; (d) deformed shape of experimental results.

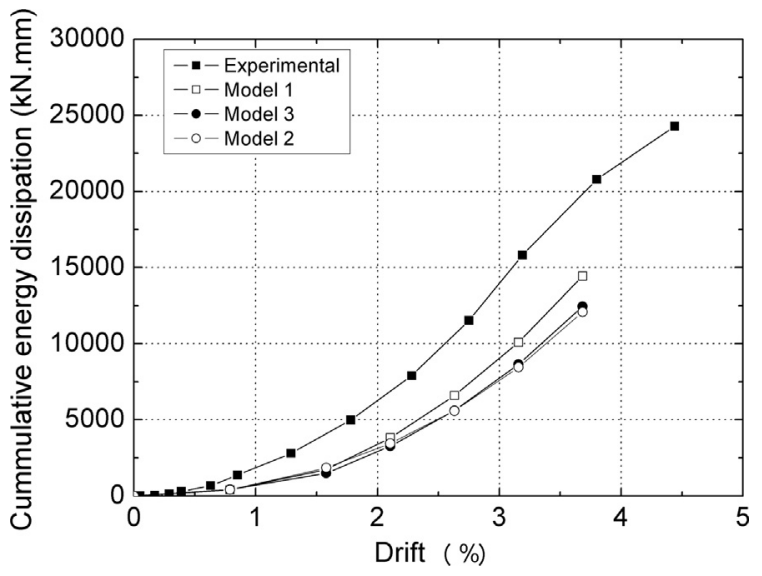

Fig. 15. Comparison of cumulative energy dissipation between timber frame models.

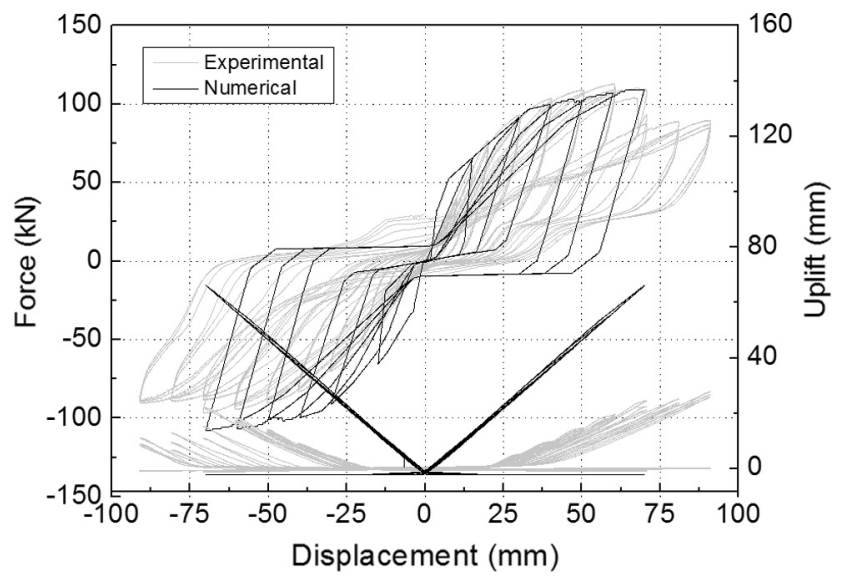

Fig. 16. Comparison between experimental and numerical in-plane cyclic response of timber frame with brick infill UIW50.

maximum drift of around 5\%, with increments on the lateral drifts of 1\% (Fig. 18a). The values of the lateral load capacity and the lateral initial stiffness for the different models having different height to length ratio are indicated in Table 2.
The different geometric models were built by assembling different numbers of reference timber frame cell $[1 \times 1]$ in height and length, aiming at obtaining more squat or slender walls, see Fig. 17.

Squat walls were obtained by having two cells in length (models [ $1 \times 2],[2 \times 2]$ and $[3 \times 2])$ and slender walls were obtained by adding the reference timber frame cell in height (models $[1 \times 1]$, $[2 \times 1]$ and $[3 \times 1])$.

The analysis of the lateral resistance and lateral stiffness indicates that as expected more squat walls present considerable initial stiffness and higher resistance. The increase on the slenderness induces lower stiffness and significantly lower lateral resistance.

The evolution of the lateral stiffness and resistance with increasing height to length ratios is decreasing, see Fig. 18b. Two different values for load capacity and stiffness are presented for models $1 \times 1$ and $2 \times 2$ having the same height to length ratio equal to 1 . This disparity is due to the difference in total length of the walls. The analysis of the cumulative dissipated energy for the timber frame walls with different geometric configuration revealed that more squat walls $(n \times 2$, with $n$ varying from 1 to 3 , representing $n$ rows and 2 columns) have considerably higher dissipation than slender walls $(\mathrm{n} \times 1$, with $\mathrm{n}$ varying from 1 to 3) (Fig. 19). These results appear to indicate that the performance of timber frame walls in masonry buildings is greatly dependent on their geometry.

\section{Conclusions}

Timber-framed structures perform as earthquake-resistant construction mostly due to their ability to dissipate large amounts of energy at connections. From the experimental campaigns on a full-scale timber frame walls under in-plane cyclic loading, it was evident that they experienced a predominant rocking (flexural) mechanism with strength degradation and pinching. Energy dissipation is also concentrated within the central connection (Cross of St. Andrew) due to elongations of diagonals caused by the lateral loading resulting in shear concentrations within the middle beam.

The identified locations of nonlinearity are used in the development of a detailed numerical model of the timber frame wall with and without infill based on a macro-modelling approach, being calibrated with experimental results. A reasonable agreement was found between the experimental and numerical response of the wall, particularly as concerns the initial stiffness and lateral strength. A good trend in energy 


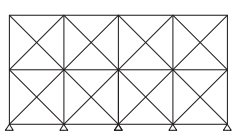

[1x2]

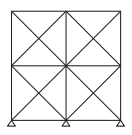

[1x1]

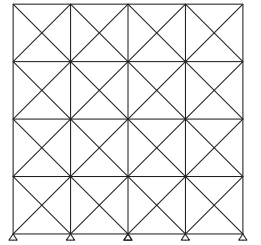

[2×2]

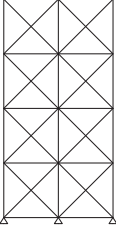

$[2 \times 1]$

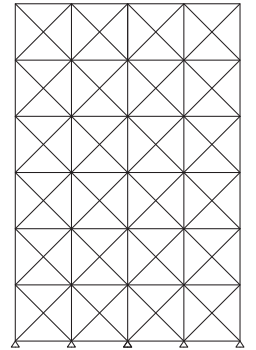

[3×2]

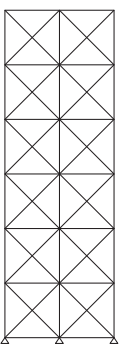

[3×1]
Models [nx2]

Models [nx1]

Fig. 17. Wall configurations studied.

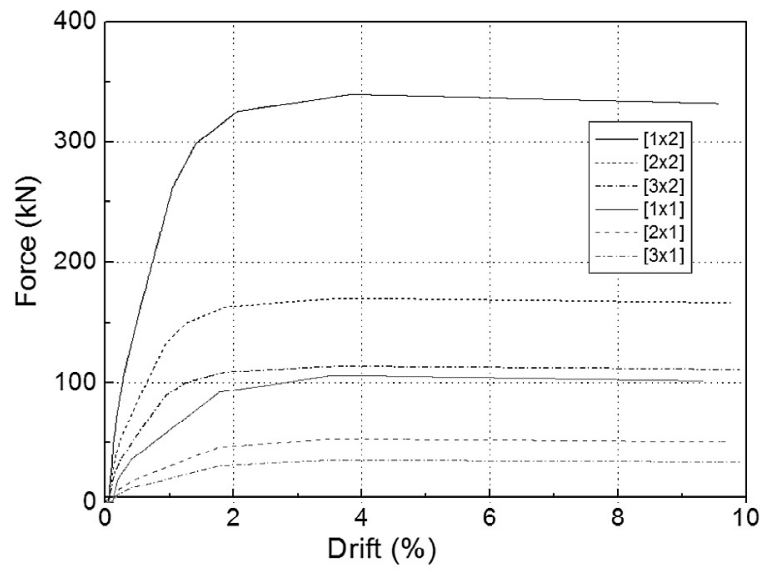

(a)

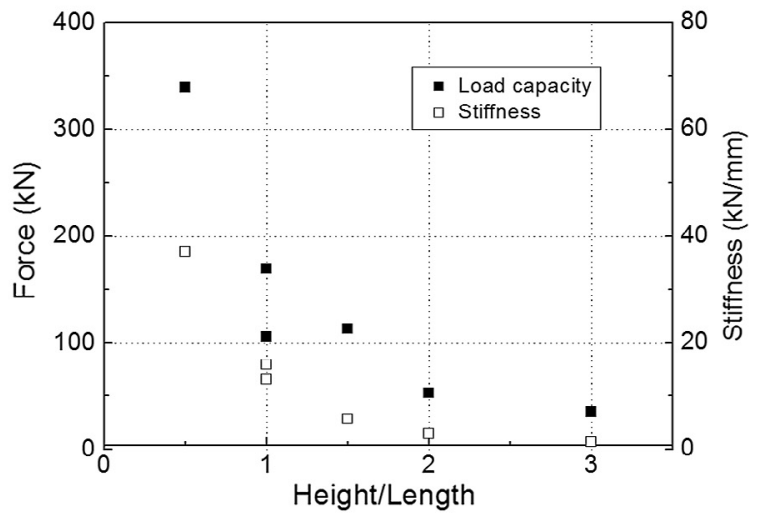

(b)

Fig. 18. (a) Influence of the height to length ratio on the lateral response of timber frame wall with brick infill; (b) initial stiffness and load capacity.

Table 2

Initial stiffness and load capacity for different configurations of timber frame wall with brick infill.

\begin{tabular}{llll}
\hline Wall & Aspect ratio [H/L] & Maximum load $[\mathrm{kN}]$ & $\begin{array}{l}\text { Initial stiffness, } \mathrm{K}_{\mathrm{in}}[\mathrm{kN} / \\
\mathrm{mm}]\end{array}$ \\
\hline $1 \times 2$ & 0.5 & 340.25 & 53.13 \\
$1 \times 1$ & 1 & 105.56 & 16.00 \\
$2 \times 2$ & 1 & 170.12 & 18.54 \\
$3 \times 2$ & 1.5 & 113.41 & 8.41 \\
$2 \times 1$ & 2 & 52.78 & 4.19 \\
$3 \times 1$ & 3 & 35.18 & 1.70 \\
\hline
\end{tabular}

dissipation was also found, even if the models underestimate total cumulative energy dissipated. The numerical deformation patterns are also compatible with the deformation observed in the experimental tests, but the uplift is overestimated in the numerical model.

An additional numerical study was developed to analyse the lateral behavior of timber frame walls with different geometries, namely by varying the height to length ratio. The analysis of the initial stiffness, lateral load capacity and global load-drift displacement was carried out. It was found that an increasing height to length ratio (slender walls) led to decreasing initial stiffness and lateral strength. On the contrary, timber frame walls with a decreasing height to length ratio (squat walls) presented greater energy dissipation. Both lateral load capacity and initial stiffness exhibit an exponential variation with increasing lateral drift.

These results appear to indicate that the proposed detailed macromodel approach can be used in the numerical simulation of traditional timber frame walls. Future developments of this work will concern the calibration of a simplified macro-model approach with a simplified geometry and non-linearities concentrated in only one spring for each wall, which would have great advantages when large timber frame structures are to be analyzed. With such a model, the modelling of whole buildings can be carried out with the simplified macro-models to represent internal timber-framed shear walls and with shell elements to represent the external masonry walls.

\section{Acknowledgments}

The research has been supported by the Portuguese Foundation of Science and Technology through grant SFRH/BPD/99891/2014 and the SAHC Consortium. 


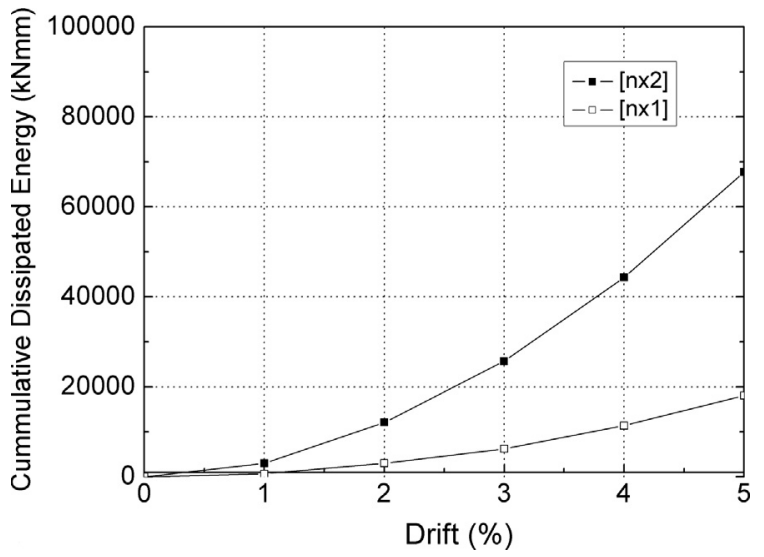

Fig. 19. Influence of height to length ratio on cumulative dissipated energy of timber frame wall with brick infill.

\section{Appendix A. Supplementary material}

Supplementary data associated with this article can be found, in the online version, at http://dx.doi.org/10.1016/j.engstruct.2018.03.039.

\section{References}

[1] Güçhan NS. Observations on earthquake resistance of traditional timber-framed houses in Turkey. Build Environ 2007;42:840-51.

[2] Ruggieri N, Tampone G, Zinno R. In-plane vs out-of-plane "behaviour" of an Italian timber framed system: the borbone constructive system. historical analysis and experimental evaluation. Int J Arch Herit 2015;6:696-711.

[3] Vintzileou E, Zagkotsis A, Repapis C, Zeris Ch. Seismic behaviour of the historical structural system of the island of Lefkada, Greece. Constr Build Mater 2007;21:225-36.

[4] Langenbach R. From "Opus Craticium" to the "Chicago Frame": earthquake-resistant traditional construction. Int J Arch Herit 2007;1(1):29-59.

[5] Mascarenhas J. Constructive systems - V. Livros Horizonte; 2004, Lisbon, Portugal.

[6] Vasconcelos G, Poletti E. Traditional timber frame walls: mechanical behavior analysis and retrofitting. In: Panagiotis VP, Asteris G, editors. Handbook of research on seismic assessment and rehabilitation of historic structures. IGI Global; 2015. p. 30-59.

[7] Tsakanika-Theohari E, Mouzakis H. A post-Byzantine mansion in Athens. Restoration project of the timber structural elements. In: Proceedings of WCTE world conference on timber engineering, June 20-24, 2010 Riva Del Garda, Trento, Italy.

[8] Torrealva D, Vicente E. Experimental evaluation of seismic behavior of Quincha walls from the historic centre of Lima - Peru. In: Proceedings of 15th world conference on earthquake engineering (15WCEE), 24-28 September 2012, Lisbon,
Portugal.

[9] Quinn N, D'Ayala D, Descamps D. Structural characterisation and numerical modelling of historic Quincha Walls. Int Arch Herit 2015. http://dx.doi.org/10.1080/ 15583058.2015.1113337.

[10] English Heritage. Practical building conservation. Timber. Farnham (England): Ashgate Pulishing Ltd.; 2012.

[11] Copani P. Timber-frame buildings in Scandinavia: high deformation prevent the system from collapse. From Material to Structure - Mechanical Behaviour and Failures of the Timber Structures ICOMOS IWC - XVI International Symposium. Florence, Venice and Vicenza 11-16 November; 2007.

[12] Poletti E, Vasconcelos G. Seismic behaviour of traditional timber frame walls: experimental results on unreinforced walls. Bull Earthq Eng 2015;13(3):885-916.

[13] Aktas YD, Akyüz U, Türer A, Erdil B, Güçhan NS. Seismic resistance evaluation of traditional Ottoman timber-frame Hımıs houses: frame loadings and material tests. Earthquake Spectra 2013. http://dx.doi.org/10.1193/011412EQS011M.

[14] Vieux-Champagne F, Sieffert Y, Grange S, Polastri A, Ceccotti A, Daudeville I. Experimental analysis of seismic resistance of timber-framed structures with stones and earth infill. Eng Struct 2014;69:102-15.

[15] Dutu A, Sakata H, Yamazaki Y, Shindo T. In-plane behavior of timber frames with masonry infills under static cyclic loading. J Struct Eng ASCE 2016;142(2).

[16] Meireles H, Bento R, Cattari S, Lagomarsino S. A hysteretic model for "frontal" walls in Pombalino buildings. Bull Earthq Eng 2012;10:1481-502.

[17] Gonçalves A, Ferreira JG, Guerreiro L, Branco F. Experimental characterization of Pombalino "frontal" Wall cyclic behaviour. In: Proceedings of the 15th world conference on earthquake engineering (15WCEE); 2012.

[18] Kouris L, Kappos AJ. Detailed and simplified non-linear models for timber-framed masonry structures. J Cult Heritage 2012;13(1):47-58.

[19] Branco J, Descamps T. Analysis and strengthening of carpentry joints. Constr Build Mater 2016;97:34-47.

[20] Ceccotti A, Sandhaas C. A proposal for a standard procedure procedure to establis the seismic behaviour factor q of timber buildings. In: Proceedings of WCTE world conference on timber engineering, June 20-24, 2010 Riva Del Garda, Trento, Italy.

[21] Kouris LAS, Meireles H, Bento R, Kappos AJ. Simple and complex modelling of timber-framed masonry walls in Pombalino buildings. Bull Earthq Eng 2014:12:1777-803.

[22] Casagrande D, Rossi S, Sartori T, Tomasi R. Proposal of an analytical procedure and a simplified numerical model for elastic response of single-storey timber shearwalls. Constr Build Mater 2016;102:1101-12.

[23] Mazzoni S, McKenna F, Scott MH, Fenves GL. Open system for earthquake en gineering simulation user command language manual. Berkeley: University of California, Pacific Earthquake Engineering Research Centre; 2006.

[24] Aranha C, Branco J, Lourenço P, Flatscher G, Schickhofer G. Finite element modelling of the cyclic behaviour of CLT connectors and walls. In: WCTE 2016, World conference on timber engineering. Vienna, Austria.

[25] Schneider J, Shen Y, Stiemer SF, Tesfamariam S. Assessment and comparison of experimental and numerical model studies of cross-laminated timber mechanical connections under cyclic loading. Constr Build Mater 2015;77:197-212.

[26] Poletti E, Vasconcelos G, Branco JM, Koukouviki AM. Performance evaluation of traditional timber joints under cyclic loading and their influence on the seismic response of timber frame structures. Constr Build Mater 2016;127:321-34.

[27] Folz Filiatrault. Seismic analysis of woodframe structures. I: Model formulation. J Struct Eng 2004;130(9):1353-60.

[28] Poletti E. Characterization of the seismic behaviour of traditional timber frame walls. Universidade do Minho; 2013. 